\title{
Development of prognostic index for primary supratentorial intracerebral tumours
}

\author{
J L Hutton, D F Smith, D Sandemann, P M Foy, M D M Shaw, I R Williams, \\ DW Chadwick
}

\begin{abstract}
The clinical course of intrinsic supratentorial tumours is variable. Prediction of outcome would be useful in defining patients for specific treatment policies. $A$ retrospective analysis of 560 patients with intrinsic supratentorial tumours was performed. Proportional hazards models for survival were derived by using a stepwise selection procedure with only clinical and CT features as possible explanatory variables. The variables of prognostic importance were age, a first symptom of epilepsy, focal signs at presentation, a cystic lesion on CT scan, and duration of symptoms before presentation. The model defined a group with a good prognosis (score $\leqslant 9, n=211$ ) and a group with a poor prognosis (score $>9, n=344$ ). The median survival was 27 months for those with a score $\leqslant 9$ or less and three months for those with score $>9$. An alternative model, not including duration of symptoms, is also capable of defining groups with long (score $\leqslant 16, n=234$ ) and short (score $>16, n=325$ ) survival. The model may provide a means of classifying patients for inclusion in prospective randomised studies.
\end{abstract}

Intrinsic supratentorial malignant tumours are associated with epilepsy in about one third of cases, ${ }^{1}$ and in a considerable proportion of cases seizures are the only initial manifestation. Many clinicians believe that patients with such tumours have a favourable prognosis. This impression has been supported by the findings of a number of retrospective surveys. Smith $e t$ $a l^{2}$ found a median survival of 37 months for patients presenting with epilepsy and six months for those presenting with other symptoms. Patients presenting with epilepsy were more likely to have no neurological signs and a non-enhancing low density on CT. The most important factors determining an adverse prognosis were increasing age, focal signs at presentation, and enhancing lesions on CT, while presentation with epilepsy and cysts on CT suggested a favourable prognosis.

Whether the benefits of early and aggressive management (including resective surgery and radiotherapy) in neurologically intact patients justify the risks associated with this policy is unknown. Opinions differ widely with neurosurgeons ${ }^{3}$ and radiotherapists ${ }^{4}$ advocating an aggressive approach while neurologists tend to prefer conservative management. Smith et $a l^{2}$ failed to demonstrate any positive beneficial treatment effects either in survival or control of epilepsy. It was clear, however, that patients with adverse clinical and CT prognostic factors received early biopsy and radiotherapy thus potentially underestimating the effectiveness of this treatment.

No prospective randomised study of conservative $v$ aggressive management in this group has been performed despite identification of the need for such a study. ${ }^{5-7}$ The evidence that postoperative radiotherapy prolongs survival in malignant glioma in patients surviving surgery in good condition is convincing $^{8-10}$ but its role in low-grade glioma is disputed and certainly not established. ${ }^{411}$ Therefore it is these patients, who are likely to have benign lesions, who should be studied in a prospective randomised trial of the two management policies.

To identify patients with a fairly favourable prognosis, we examined our database and developed an internally valid prognostic model based on pretreatment (clinical and radiological) variables only. This could help the clinical management of patients and might be useful in identifying patients with different expected survivals for inclusion in future prospective randomised studies.

\section{Subjects and methods}

The methods and results of the retrospective study from which this prognostic index has been derived are described elsewhere. ${ }^{2}$ Briefly, a database containing details of 560 patients with intrinsic supratentorial tumours, presenting to both neurologists and all but one of the neurosurgeons between 1975 and 1989 , was compiled. This included 164 patients whose

Table 1 Variables selected before biopsy as predictors of survival and those selected in patients surviving $<120$ months

\begin{tabular}{|c|c|c|}
\hline Variable & $\begin{array}{l}\text { Coefficient } \\
\text { (beta) }\end{array}$ & $\begin{array}{l}\text { Standard } \\
\text { error }\end{array}$ \\
\hline \multicolumn{3}{|c|}{ Before biopsy } \\
\hline $\begin{array}{l}\text { Age (years) } \\
\text { First symptom: epilepsy } \\
\text { Focal signs } \\
\text { Duration of symptoms (months) } \\
\text { Cyst on CT }\end{array}$ & $\begin{array}{r}0.031 \\
-0.808 \\
0.479 \\
-0.007 \\
-0.240\end{array}$ & $\begin{array}{l}0.003 \\
0.142 \\
0.118 \\
0.003 \\
0.111\end{array}$ \\
\hline \multicolumn{3}{|c|}{ In patients surviving $<120$ months } \\
\hline $\begin{array}{l}\text { Age (years) } \\
\text { First symptom: epilepsy } \\
\text { Focal signs } \\
\text { Enhancement on CT } \\
\text { Cyst on CT } \\
\text { Duration of symptoms } \\
\text { Low density on CT } \\
\text { Mental symptoms }\end{array}$ & $\begin{array}{r}0.029 \\
-0.689 \\
0.474 \\
0.705 \\
-0.396 \\
-0.007 \\
-0.248 \\
0.208\end{array}$ & $\begin{array}{l}0.004 \\
0.155 \\
0.118 \\
0 \cdot 170 \\
0 \cdot 113 \\
0.003 \\
0 \cdot 116 \\
0.105\end{array}$ \\
\hline
\end{tabular}


Table 2 Coefficients of scores for prognostic index *

\begin{tabular}{lclc}
\hline Variable & Coefficient beta (SE) & Category & Scores \\
\hline Age (years) & $0.564(0.067)$ & $<45$ & 0 \\
& & $45-59$ & 6 \\
Focal signs & $0.446(0.119)$ & Absent & 12 \\
First symptom & $0.889(0.140)$ & Present & 4 \\
Cyst on CT scan & $-0.298(0.111)$ & Not epilepsy & 9 \\
Duration of symptoms (months) & $-0.156(0.071)$ & Absent & 0 \\
& & 0 & 0 \\
& & $0<$ duration $<2$ & -2 \\
& & duration $>2$ & -4
\end{tabular}

^Each patient was assigned to group corresponding to total score: group 1-total score (range) -7 to $-1 ; 2-0$ to $6 ; 3-7$ to $9 ; 4-10$ to $13 ; 5-14$ to $16 ; 6-17$ to $20 ; 7-21$ to 25 .

first symptom was epilepsy and 396 patients with other presenting symptoms. Diagnosis of intrinsic supratentorial tumour was based on clinical and radiological findings with histological confirmation of tumour in $356(63.6 \%)$ cases. The proportion of histologically verified tumours was $100(61 \%)$ in the group presenting with epilepsy and $256(64 \cdot 6 \%)$ in those presenting with other symptoms and signs. Odds ratios showed that oligodendroglioma, which was an uncommon finding in the whole group, and low grade (Kernohan 1 or 2) tumours were more common in the group presenting with epilepsy. The two groups were compared in terms of clinical and CT features at presentation and outcome. Survival was the time from CT diagnosis to death or final follow up with those patients not known to be dead having censored survival times. Centile survival times were calculated from Kaplan-Meier survival curves. ${ }^{12}$

Proportional hazards models ${ }^{13}$ for survival from diagnosis were calculated by using a stepwise selection procedure, with information available before biopsy as possible explanatory variables, ${ }^{14}$ Cox's proportional hazards model yields a coefficient (beta) for each explanatory

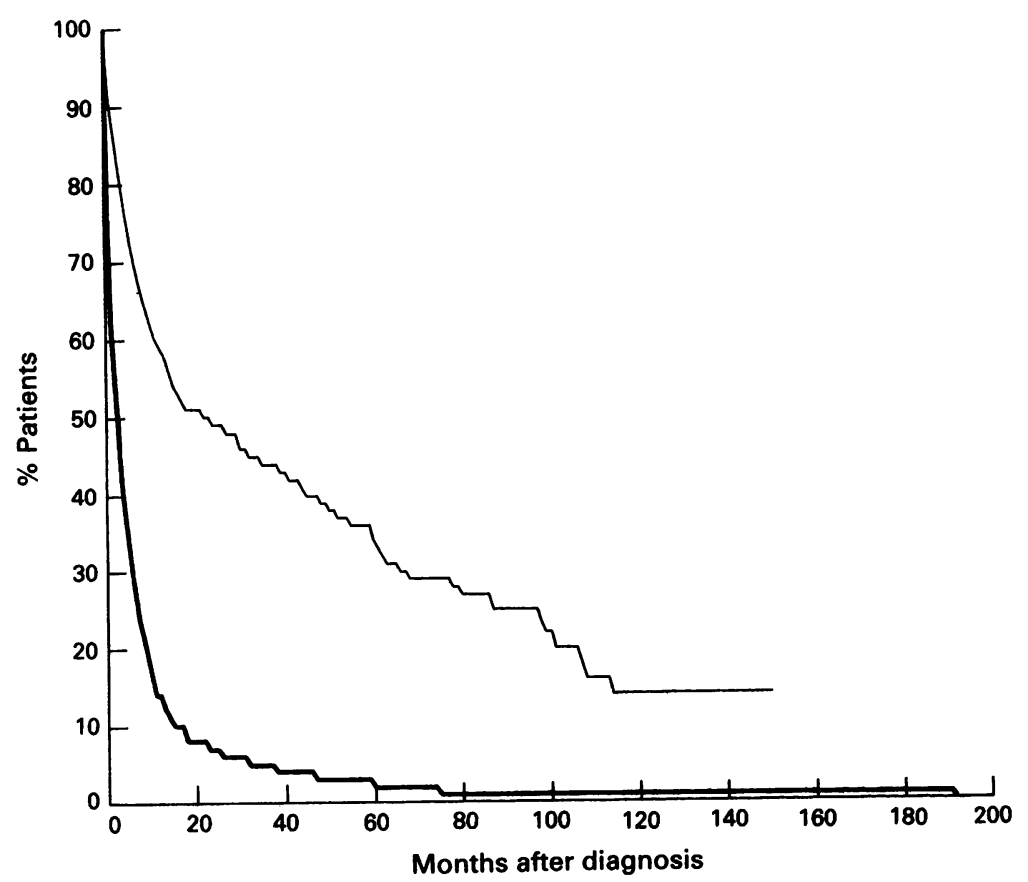

Figure 1 Actuarial survival for all survival data. (- Patients scoring $\leqslant 9(n=215)$; - patients scoring $>9(n=344))$.
Table 3 Comparison of survival of groups of patients defined by score

\begin{tabular}{|c|c|c|c|c|c|c|c|}
\hline \multirow[b]{2}{*}{ Group } & \multirow{2}{*}{$\begin{array}{l}\text { No of } \\
\text { Patients }\end{array}$} & \multirow{2}{*}{$\begin{array}{l}\text { No of } \\
\text { Deaths }\end{array}$} & \multicolumn{3}{|c|}{ Survival (months)* } & \multicolumn{2}{|c|}{$\%$ Survival } \\
\hline & & & $25 \%$ & $50 \%$ & $75 \%$ & $\begin{array}{l}\text { One } \\
\text { year }\end{array}$ & $\begin{array}{l}\text { Two } \\
\text { years }\end{array}$ \\
\hline $\begin{array}{l}1 \\
2 \\
3 \\
4 \\
5 \\
6 \\
7\end{array}$ & $\begin{array}{r}70 \\
81 \\
63 \\
71 \\
51 \\
81 \\
142\end{array}$ & $\begin{array}{r}24 \\
57 \\
52 \\
61 \\
49 \\
79 \\
142\end{array}$ & $\begin{array}{r}34 \\
3 \\
3 \\
2 \\
2 \\
1 \\
1\end{array}$ & $\begin{array}{r}99 \\
15 \\
9 \\
6 \\
6 \\
3 \\
2\end{array}$ & $\begin{array}{r}108 \\
66 \\
41 \\
15 \\
11 \\
7 \\
4\end{array}$ & $\begin{array}{r}92 \\
53 \\
45 \\
30 \\
21 \\
10 \\
1\end{array}$ & $\begin{array}{r}74 \\
46 \\
29 \\
17 \\
11 \\
2 \\
0\end{array}$ \\
\hline
\end{tabular}

ॠFigures indicate number of months until $25 \%, 50 \%$ (median), and $75 \%$ of patients in each group died allowing for censoring.

variable from which the relative risk of mortality, associated with that variable, may be calculated. Once the model has been selected, continuous variables were categorised and a score indicating the prognosis was derived from the coefficients of the signs and symptoms. The beta coefficient for each variable is rounded off to the nearest decimal place and then multiplied by ten to give a variable score. The total prognostic score for each individual is the sum of the variable scores. Each patient is assigned to a prognostic group defined by their total score. The survival rates of prognostic groups defined by using this score were then determined.

Cross-validation was used to assess the extent to which this score is dependent on a specific data set. The data were split into two subsets by using random numbers, three such partitions of the data being created. Statistical models were developed, by the stepwise procedure, for each of the subsets. This enables comparison of the relative prognostic importance of different variables. The more often a variable is selected for different partitions the more confident one can be about the prognostic significance of that variable. Furthermore, such a variable would probably be of predictive value in a new group of patients. Scores were derived for both subsets of each partition and the score for one subset was used to divide the complementary subset into prognostic groups predicted to have good, fair, or poor survival. To assess the validity of these predictions the actual survival rate of these groups was found. The influence of the five patients with survival longer than 10 years was assessed by repeating the above procedure with these patients excluded.

Results

The selected explanatory variables and their

Table 4 Number of patients at risk after diagnosis according to prognostic index

\begin{tabular}{lrrrr}
\hline \multicolumn{5}{l}{ Test score } \\
\cline { 2 - 5 } Months after diagnosis & $\leqslant 9$ & $>9$ & $\leqslant 16$ & $>16$ \\
\hline 0 & 215 & 344 & 234 & 325 \\
10 & 130 & 48 & 165 & 13 \\
20 & 96 & 21 & 114 & 3 \\
40 & 72 & 8 & 79 & 1 \\
80 & 17 & 3 & 18 & 0 \\
120 & 3 & 1 & 4 & 0 \\
\hline
\end{tabular}


Table 5 Frequency with which variables are selected with all data and three randomly generated partitions

\begin{tabular}{|c|c|c|c|c|c|c|}
\hline \multirow[b]{2}{*}{ Variable } & \multirow[b]{2}{*}{ All data } & \multicolumn{5}{|c|}{ Partitions } \\
\hline & & $\overline{1 a}$ & $1 b$ & $2 a$ & $2 b 3$ & $3 a 3 b$ \\
\hline $\begin{array}{l}\text { Age } \\
\text { First symptom: epilepsy } \\
\text { Focal signs } \\
\text { Duration symptoms } \\
\text { CT cyst } \\
\text { CT enhancement } \\
\text { CT low density } \\
\text { Mental signs }\end{array}$ & $\begin{array}{l}\star \\
\star \\
\star \\
\star \\
\star\end{array}$ & $\begin{array}{l}\star \star \\
\star \\
\star \\
\star\end{array}$ & & $\begin{array}{l}\star \\
\star \\
\star\end{array}$ & $\begin{array}{ll} & \\
\star & \\
\star & \\
\star & \\
\star & \\
\star & \end{array}$ & 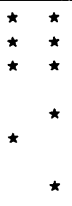 \\
\hline
\end{tabular}

coefficients in decreasing order of importance from the full data set were age, first symptom of epilepsy, focal signs at presentation, a cystic lesion on CT, and the duration of symptoms before presentation (table 1). To distinguish further which factors discriminate between groups the five patients with long survival ( $>10$ years) were excluded and subsequent analysis indicated that enhancing and low density lesions on CT and mental symptoms at presentation may also be included as explanatory variables. A prognostic index was derived from these variables by categorising the patients as young ( $<45$ years), middle aged (45-59 years), and old ( $>59$ years) and the duration of symptoms as negligible (a few days or less), short (up to two months), and prolonged (longer than two months). Scores were assigned to reflect the coefficients in the hazard function, and the total score (arithmetic sum) was used to define seven groups of patients with increasingly poor prognosis (table 2 ). The survival experience of these groups does decline (table 3 ) with the first group having a median survival of more than eight years and the seventh group a median survival of two months. Figure 1 shows the clearly different survival experience of patients divided into two groups according to prog-

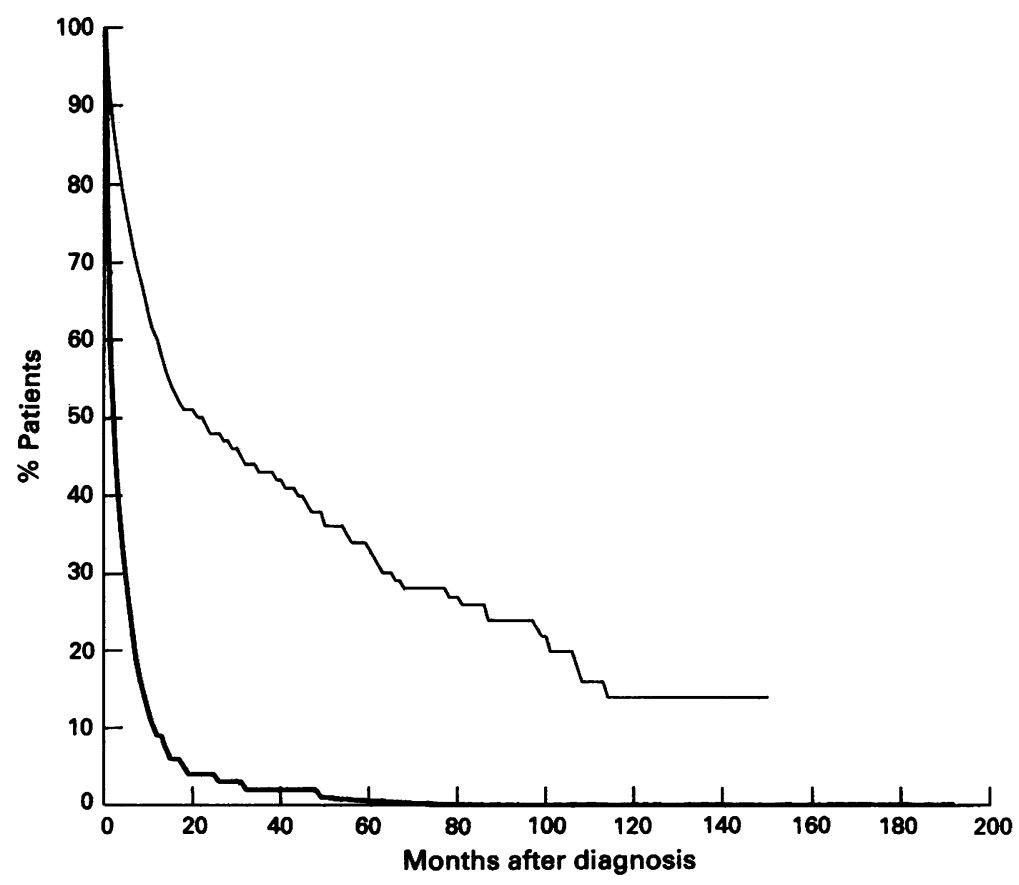

Figure 2 Actuarial survival for all survival data. (- Patients scoring $\leqslant 16$ $(n=234)$; - patients scoring $>16(n=325))$.
Table 6 Scores derived from first partition of data with age and duration of symptoms categorised (whole dataset). Score based on second subset of data

\begin{tabular}{llr}
\hline Variable & Categories & Score \\
\hline First symptom & Not Epilepsy & 0 \\
& Epilepsy & -11 \\
Age (years) & $<45$ & 0 \\
& $45-59$ & 5 \\
Mental signs & A59 & 10 \\
& Absent & 0 \\
CT cyst & Present & 4 \\
& Absent & 0 \\
Focal signs & Present & -5 \\
& Absent & 0 \\
& Present & 4 \\
\hline
\end{tabular}

Group defined by total score: group (total score) good $(<-10)$; fair $(-9,1)$; poor $(>2)$.

nostic score (score $\leqslant 9$; score $>9$ ) and table 4 indicates the number of patients in each group who are at risk at different durations of follow up.

Eight variables were selected as predictors of survival for at least one random subset. The combinations in which they occur are shown in table 5. Between three and six variables may be selected. Age was always selected with a coefficient varying from 0.024 to 0.040 and a hazard ratio of 1.74 to 2.51 per decade. Whether or not the first symptom was epilepsy is consistently important with hazard ratios for those presenting with epilepsy ranging from 0.05 to 0.30 in these partitions. Focal signs at presentation was also consistently identified as an adverse prognostic factor with hazard ratios of 2.47 to 4.53 . Cystic, enhancing, and low density lesions on CT may be combined with mental signs at presentation to replace duration of symptoms in predicting outcome (table 5).

A further method of validation was used in which the whole data set was divided into two subsets. Scores derived from each of these subsets are given in table 6 and used to define three prognostic groups: good, fair, and poor. The accuracy of the scores was then tested in the other subset (table 7). Scores on one subset of data may be used to predict which patients from the other subset are likely to have a fairly long life and those who will die within a few months. Age, the first symptom, and focal signs at presentation remain important when those with long survival are excluded (table 8). Additional variables were selected into the explanatory models for some of the subsets of the partitions. Again these appear to be variables which are indicators of the duration of symptoms. An alternative score, which does not include duration of symptoms, is therefore presented in table 9. Using a total score of $\leqslant 16$ to define a good prognosis gives two groups with very different survival experience (figure 2). The number of patients in each group who are at risk at different durations of follow up is shown in table 4. The difference in survival is slightly greater than for the groups defined by the previous score.

\section{Discussion}

This data set is unusual for several reasons. During the early years of data collection (1978-86) there was only one CT scanner in the Merseyside region and virtually all patients with intrinsic supratentorial tumours had to 
Table 7 Comparison of survival of patients in these groups defined by score of alternative partitions

\begin{tabular}{|c|c|c|c|c|c|c|c|}
\hline \multirow[b]{2}{*}{ Group } & \multirow[b]{2}{*}{ No of patients } & \multirow[b]{2}{*}{ No of Deaths } & \multicolumn{3}{|c|}{ Survival (months)* } & \multicolumn{2}{|c|}{$\%$ Survival } \\
\hline & & & $25 \%$ & $50 \%$ & $75 \%$ & one year & two years \\
\hline \multicolumn{8}{|c|}{ Validation of first subset $(n=285$} \\
\hline Good & 94 & 57 & 6 & 42 & 99 & 61 & 55 \\
\hline Fair & 89 & 82 & 2 & 5 & 10 & 21 & 12 \\
\hline Poor & 102 & 101 & 1 & 2 & 4 & 6 & 4 \\
\hline \multicolumn{8}{|c|}{ Validation of second subset $(n=275)$} \\
\hline Good & 103 & 58 & 9 & 33 & 98 & 70 & 57 \\
\hline Fair & 107 & 102 & 1 & 4 & 11 & 21 & 7 \\
\hline Poor & 65 & 65 & 1 & 3 & 4 & $\mathbf{0}$ & 0 \\
\hline
\end{tabular}

${ }^{\star}$ Figures indicate number of months until $25 \%, 50 \%$ (median), and $75 \%$ of patients in each group died allowing for censoring.

come through the regional department for diagnosis and initial management. Such patients presented to both neurologists and neurosurgeons, with a wide spectrum of presenting symptoms and signs, and both conservative and aggressive management policies were used. While one neurosurgeon did not contribute this is otherwise a fairly complete sample. A few clinical and radiological variables were found to be important in predicting outcome. Using cross-validation procedures the factors which were consistently selected as being of prognostic importance were age at presentation, presentation with epilepsy, and focal neurological deficit.

Our present models could be criticised because they take no account of potential treatment effects in influencing outcome. The main purpose of the model is, of course, the identification at diagnosis of patients with different prognoses. The potential treatment effects influencing outcome have been examined in another publication. ${ }^{2}$ Patients with epilepsy and therefore a good outcome were as likely to receive resective surgery or radiotherapy as those with other modes of presentation associated with a poorer outcome. Radiotherapy did improve survival in the complete data set but not in those presenting with epilepsy. There is a suggestion that at least some of the apparent effects of radiotherapy in our patients could have been due to selection of patients with better prognoses for this treatment. ${ }^{7}$ While prospective validation of our models will need to take into account treatment effects, the evidence above would suggest that pretreatment predictors derived from our data set are accurate in defining prognosis.

Patients with good, intermediate, and poor prognoses may be differentiated by using a score derived from a proportional hazards

Table 8 Frequency with which variables are selected using three randomly generated partitions of the data set (survival $\leqslant 120$ months)

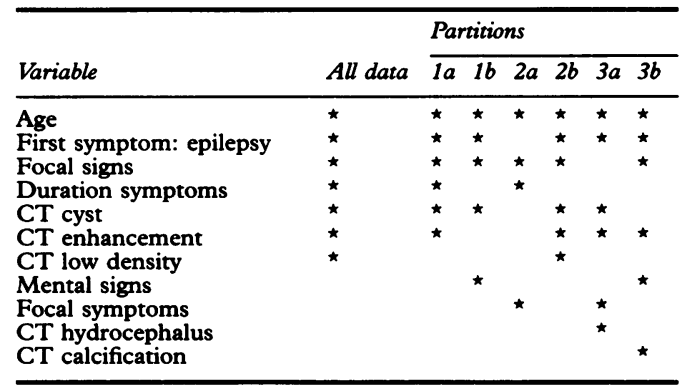

Table 9 Score for prognostic index which does not use duration of symptoms

\begin{tabular}{llr}
\hline Variable & Categories & Score \\
\hline Age (years) & $<45$ & 0 \\
& $45-59$ & 5 \\
Focal signs & $>59$ & 10 \\
First symptom & Absent & 0 \\
Cyst on CT & Present & 5 \\
Enhancement on CT & Not epilepsy & 7 \\
& Epilepsy & 0 \\
Low density on CT & Absent & 0 \\
Calcification on CT & Absent & -4 \\
& Aresent & 0 \\
Mental signs & Present & 7 \\
& Absent & 0 \\
& Present & -3 \\
& Absent & 0 \\
& Present & -4 \\
\end{tabular}

model. It shows a high degree of internal validity. The MRC brain tumour working party, ${ }^{15}$ using a different population of patients with histologically proven high grade malignant glioma, also found age at presentation and a history of seizures to be important prognostic factors suggesting some external validity for our model. The model does require prospective testing, however, in a new population of patients.

The prognostic model is easy to use and has several potential applications. In a clinical setting the prognostic score allows segregation of patients with very good prognoses from those with very bad prognoses, which clearly has implications for counselling of both patients and their relatives. It could help clinicians in deciding what would be the most appropriate management for individual patients. Finally, it may provide a means of classifying patients for inclusion in prospective randomised studies of management policies.

1 Lund M. Epilepsy in association with intracranial tumour. Acta Psych Neurol Scand 1952 (suppl):81.

2 Smith DF, Hutton JL, Sandemann DR, et al. The prognosis of primary intracerebral tumours presenting with epilepsy: The outcome of medical and surgical management. f Neurol Neurosurg Psychiatry 1991;54:915-20.

3 Laws ER, Taylor WF, Clifton MB, Okazaki H. Neurosurgical management of low-grade astrocytoma of the cerebral hemispheres. $\mathcal{F}$ Neurosurg 1984;61:665-73.

4 Shaw EG. Low-grade gliomas: to treat or not to treat? A radiation oncologist's viewpoint. Arch Neurol 1990;47:1 138-9.

5 Wroe SI, Foy PM, Shaw MDM, et al. Differences between neurological and neurosurgical approaches to the manneurological and neurosurgical approaches to the management of malign:

6 Cairncross JG, Laperriere NJ. Low-grade glioma: to treat or not to treat. Arch Neurol 1989;46:1238-9.

7 Sandemann DR, Sandemann AP, Buxton P, et al. The management of patients with an intrinsic supratentorial brain tumour. Br $\mathcal{F}$ Neurosurg 1990;4:299-312.

8 Anderson AP. Post-operative irradiation of glioblastomas. Results in a randomised series. Acta Radiol 1978;17:475-84.

9 Kristiansen K, Hagen S, Kollevold T, et al. Combined modality therapy of operated astrocytomas grades 3 and 4. Confirmation of the value of post-operative irradiation and lack potentiation of bleomycin on survival time. Cancer 1981;47:649-52.

10 Walker MD, Green SB, Byar DP, et al. Randomised comparisons of radiotherapy and nitrosoureas for the treatment of malignant glioma after surgery. $N$ Engl $₹ \mathrm{Med}$ 1980;303:1323-9.

11 Cairncross JG, Laperriere NJ. Low-grade gliomas: to treat or not to treat? A reply. Arch Neurol 1990;47:1139-40.

12 Cox DR, Oakes D. Analysis of survival data. London: Chapman Hall, 1984.

13 Tibshirani R. A plain man's guide to the proportional hazards model. Clinical Investigative Medicine hazards mode

14 SAS Institute. SUGI supplemental library user's guide. Version 5. Cary; North Carolina: SAS Institute, 1986.

15 MRC Brain Tumour Working Party. Prognostic factors for high-grade malignant glioma: Development of a prognostic index. $\mathcal{F}$ Neuro Oncol 1990;9:47-55. 